\title{
Biochemical Markers of Bone Turnover in Patients with $\beta$-Thalassemia Major: A Single Center Study from Southern Pakistan
}

\author{
Sadia Sultan, ${ }^{1}$ Syed Mohammed Irfan, ${ }^{1}$ and Syed Ijlal Ahmed ${ }^{2}$ \\ ${ }^{1}$ Department of Hematology \& Blood Bank, Liaquat National Hospital and Medical College, Karachi, Pakistan \\ ${ }^{2}$ Liaquat National Medical College, Karachi, Pakistan \\ Correspondence should be addressed to Sadia Sultan; sadia.sultan@lnh.edu.pk
}

Received 31 October 2015; Revised 1 February 2016; Accepted 8 February 2016

Academic Editor: Shaji Kumar

Copyright (C) 2016 Sadia Sultan et al. This is an open access article distributed under the Creative Commons Attribution License, which permits unrestricted use, distribution, and reproduction in any medium, provided the original work is properly cited.

\begin{abstract}
Objectives. Skeletal complications in $\beta$-homozygous thalassemic patients are uncommon but often debilitating, even amongst children and adolescent patients with well maintained transfusion and chelation therapy. The aim is to evaluate the biochemical markers of bone turnover in regularly transfused thalassemic patients and its possible correlations with demographic data and hematological and biochemical markers. Methods. In this prospective cross-sectional study, $36 \beta$-thalassemia major patients were enrolled from March 2012 to March 2014. All patients underwent complete blood counts, LFTs, serum ferritin, serum calcium, phosphorus, serum albumin, alkaline phosphatase, $25-\mathrm{OH}$ vitamin $\mathrm{D}$, and parathormone (PTH) levels. Results. There were 17 males and 19 females with mean age of $12.56 \pm 5.9$ years. Hypocalcemia and hypophosphatemia were seen in $66.6 \%$ and $19.4 \%$, respectively, while $25-\mathrm{OH}$ vitamin D deficiency was present in $72.2 \%$ of thalassemic children and adolescents. Hypoparathyroidism was seen in $13.8 \%$ while hyperparathyroidism was detected in $8.3 \%$ of patients. There was direct correlation between serum phosphorus and ferritin levels $(P<0.05)$. No correlation was found between indirect bilirubin and skeletal parameters, calcium and parathyroid hormone $(P>0.05)$. Conclusions. Biochemical profile is significantly altered in patients with $\beta$-thalassemia major and bone associated biochemical abnormalities like hypocalcaemia, 25-OH vitamin D deficiency, and hypophosphatemia are not uncommon in Pakistani patients with thalassemia major.
\end{abstract}

\section{Introduction}

Thalassemia is among the most common genetic disorders worldwide. $\beta$-thalassemia is an autosomal recessively inherited hemoglobinopathy which is much prevalent in Pakistan [1]. It is anticipated that 4000 to 9000 newborns with $\beta$ thalassemia major are being added each year to the existing disease pool. The carrier frequency is 5 to $8 \%$ in our part of world and is seen uniformly in all ethnic groups [2].

$\beta$-thalassemia major is characterized by severe hemolytic anemia that entails regular blood transfusion. Life expectancy of such patients is noticeably prolonged with regular blood transfusion and appropriate iron chelation conversely; consequently, secondary hemochromatosis is still a major challenge.

In thalassemic patients, bone disease is an important cause of morbidity. Various skeletal complications including osteopenia, osteoporosis, scoliosis, rickets, spinal deformities, nerve compression, and spontaneous fractures are regularly reported in transfusion dependent thalassemics $[3,4]$. Diverse factors that contribute to skeletal disease including medullary expansion, iron accumulation, abnormal calciumphosphorus balance, high bone turnover, hormonal insufficiency, and lastly hypoxia may influence skeletal complications [5].

Deranged calcium homeostasis is a consequence of iron accumulation in $\beta$-thalassemic patients. Additionally, the defective synthesis of $25-\mathrm{OH}$ vitamin $\mathrm{D}$ and hypoparathyroidism has also been frequently reported in these patients, which have negatively affected their bone metabolism.

Our aim is to estimate the biochemical markers of bone turnover in children and adolescent thalassemic patients and to examine the association of abnormal profile with 
demographic features and hematological and biochemical markers at a tertiary care center in Southern Pakistan.

\section{Materials and Methods}

There was a prospective cross-sectional study extended from March 2012 to March 2014. 36 patients with $\beta$-thalassemia major were enrolled. An informed consent was obtained from parents/guardians in patients aged $<18$ years and from patients aged $\geq 18$ years.

Demographic data including age, gender, and medical history was recorded by thorough history from parents/ guardians and from patient's medical record. Hematological parameters including hemoglobin/hematocrit, WBC, and platelets were determined by automated Cell Dyne Ruby counter (Abbott, USA). Liver function test, serum calcium, and phosphorus were evaluated on Hitachi 912 instrument through photometric assay except for serum ferritin which was measured by immunoturbidity methodology. Serum parathormone was detected by Cobas e 411 analyzer (Roche, Japan) by chemiluminescence technique.

Patients were stratified into two groups, age of $\leq 15$ years and age of $>15$ years, to determine the possible bone profile distinction in relation to age.

The research protocol was approved by the institutional thical and research committee of Liaquat National Hospital prior to the study.

2.1. Data Analysis. A statistical analysis was carried out using IBM statistics SPSS version 21. Results were reported as the mean (SD) and independent sample $t$-tests were used to compare study groups. The descriptive statistics of bone mineral profile were measured and their correlations were calculated. Comparison of categorical data was carried by Chi-square test. $P$ value of $<0.05$ was considered as statistically significant.

\section{Results}

3.1. Demographic Profile. The study included 36 homozygous TM patients with the mean age of $12.56 \pm 5.9$ (5-24) years. 17 were males and 19 were female with the mean age of $15.5 \pm$ 5.9 and $10.1 \pm 4.5$ years, respectively. The descriptive statistics and laboratory parameters are shown in Table 1.

3.2. Hematological and Biochemical Findings. The mean hemoglobin level was $7.4 \pm 1.9 \mathrm{gm} / \mathrm{dL}$ with the hematocrit of $23.1 \pm 5.7 \%$. The mean total leukocytic count was $6.5 \pm 3.9$ $\times 10^{9} / \mathrm{L}$ and mean platelets count was $150.7 \pm 94.1 \times 10^{9} / \mathrm{L}$. Serum ferritin levels were found to be markedly elevated $4699.7 \pm 3089 \mathrm{ng} / \mathrm{mL}$. Total bilirubin and direct and indirect bilirubins were $1.53 \pm 0.8,0.56 \pm 0.5$, and $0.94 \pm 0.5 \mathrm{mg} \%$, respectively. Serum ALT and AST were $78.5 \pm 73.7$ and 68.0 $\pm 42.7 \mathrm{U} / \mathrm{L}$, respectively.

3.3. Biochemical Profile. The mean corrected calcium, phosphorus, and serum $25-\mathrm{OH}$ vitamin $\mathrm{D}$ levels were found to be $8.1( \pm 0.8), 3.1( \pm 1.28)$, and $23.1( \pm 10.7)$, respectively. The
TABLE 1: Descriptive statistics and laboratory parameters.

\begin{tabular}{lcc}
\hline Parameters & Results & References ranges \\
\hline Age (years) & $12.56 \pm 5.9$ & - \\
Hemoglobin $(\mathrm{gm} / \mathrm{dL})$ & $7.4 \pm 1.9$ & $12-16 \mathrm{gm} / \mathrm{dL}$ \\
Hematocrit $(\%)$ & $23.1 \pm 5.7$ & $36-48$ \\
Total leucocyte count & $6.5 \pm 3.9$ & $4.0-11.0 \times 10^{9} / \mathrm{L}$ \\
Platelet count & $150.7 \pm 94.1$ & $150-400 \times 10^{9} / \mathrm{L}$ \\
Total bilirubin $(\mathrm{mg} / \mathrm{dL})$ & $1.53 \pm 0.8$ & $0.3-1.2$ \\
Direct bilirubin $(\mathrm{mg} / \mathrm{dL})$ & $0.56 \pm 0.5$ & $0.1-0.5$ \\
Indirect bilirubin $(\mathrm{mg} / \mathrm{dL})$ & $0.94 \pm 0.5$ & $0.2-0.7$ \\
AST $(\mu / \mathrm{L})$ & $68.0 \pm 42.7$ & $<40$ \\
ALT $(\mu / \mathrm{L})$ & $78.5 \pm 73.7$ & $7-56$ \\
Serum ferritin $(\mathrm{ng} / \mathrm{mL})$ & $4699.7 \pm 3089$ & $20-200$ \\
Corrected serum calcium & $8.1 \pm 0.8$ & $8.6-10.2$ \\
(mg/dL) & $3.1 \pm 1.28$ & $2.5-4.5$ \\
Serum phosphorus $(\mathrm{mg} / \mathrm{dL})$ & $23.1 \pm 10.7$ & $>30$ \\
Serum vitamin D $(\mathrm{ng} / \mathrm{mL})$ & $23.5 \pm 23.0$ & $12-50$ \\
Parathyroid level $(\mathrm{pg} / \mathrm{mL})$ & &
\end{tabular}

mean parathyroid level was $23.5( \pm 23.0)$. Hypocalcemia and hypophosphatemia were seen in $66.6 \%$ and $19.4 \%$, respectively, while $25-\mathrm{OH}$ vitamin $\mathrm{D}$ deficiency was present in $72.2 \%$ of thalassemic patients. Parathormone deficiency was seen in $13.8 \%$, while hyperparathyroidism was detected in $8.3 \%$ of patients.

The correlations were also calculated among variables. There was positive correlation between low serum phosphorus and high ferritin levels $(P=0.04)$ as shown in Figure 1 . No correlation was found between indirect bilirubin and skeletal parameters, calcium, and parathyroid hormone $(P>$ $0.05)$. No statistically significant difference was noted in two stratified age groups with respect to testing parameters.

\section{Discussion}

The advent of safe transfusions with adjuvant chelation therapy has drastically prolonged the life expectancy in patients with $\beta$-thalassemia major. However, this brought various nonsiderotic, hematological, biochemical, and systemic complications. A sequence of skeletal complications including osteopenia, osteoporosis, scoliosis, skeletal deformities, bone pain, nerve compression, and spontaneous pathological fractures is not infrequent in transfusion dependent thalassemics $[3,4]$.

The anterior pituitary is principally vulnerable to iron accumulation which interrupts hormonal emission, leading to various endocrine dysfunctions. These endocrinological manifestations include hypothyroidism, hypoparathyroidism or growth failure, and gonadal damage. Hypoparathyroidism being assessed by parathormone levels, serum calcium, and phosphate has been reported in various studies with a prevalence of $4-40 \%[6,7]$. The prevalence of hypoparathyroidism $(13.8 \%)$ in our study was analogous to several studies from various countries like Iran (7.6\% to $14.6 \%)$, Oman (19\%), China (10.7\%), and Greece (13.5\%) [8-12]. Nonetheless, a 


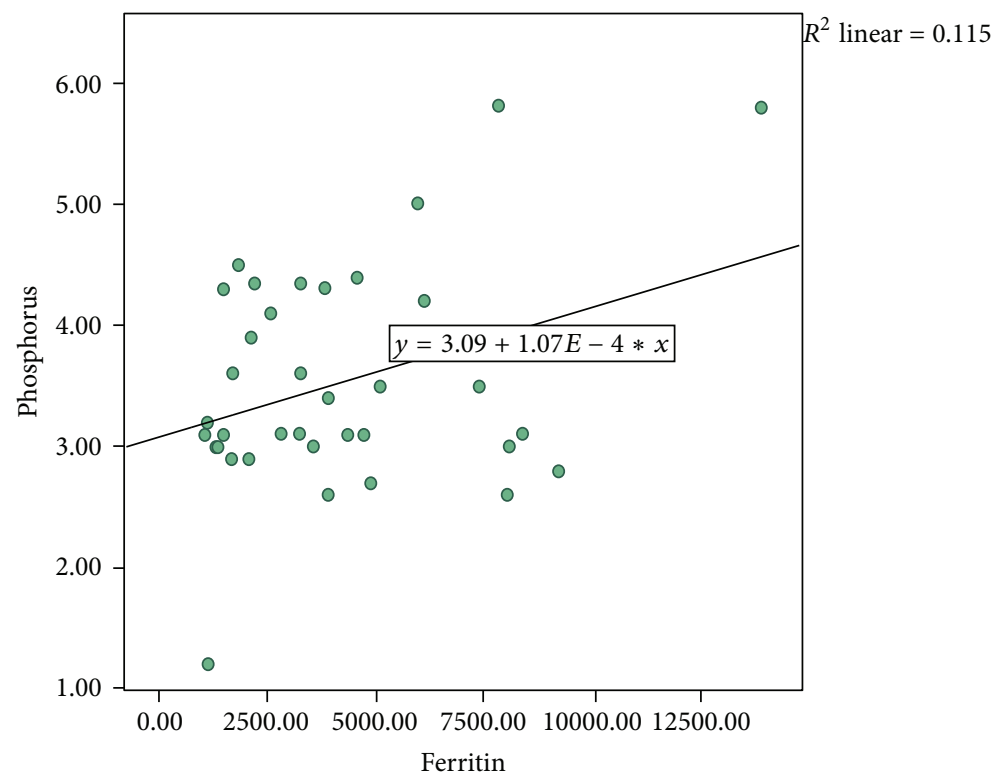

FIgure 1: Correlation of serum ferritin and phosphorus $(P=0.04)$.

retrospective study from Pakistan found a higher prevalence of hypoparathyroidism (40\%) among $\beta$-thalassemic patients [7]. The plausible explanation for this variation in prevalence of hypoparathyroidism could be attributed to small sample size $(n=10)$ and might be due to the retrospective nature of that study. One finding is the negative correlation of parathormone with indirect bilirubin determined in the present study but statistically not significant. Possibly, both deranged unconjugated bilirubin and low parathormone are sequel of hemosiderosis.

Parathormone is mainly responsible for the regulation of calcium homeostasis in body. Hypoparathyroidism can lead to hypocalcemia and osteoporosis [4]. Calcium is a very important mineral in human body playing a major role in skeletal mineralization [13]. Phosphorous has predominant effect in combination with calcium on bone growth and development, whereas osseous tissue constitutes $85 \%$ of total body phosphorus [4]. Results of the present study showed diminished level of corrected serum calcium and inorganic phosphorus in $\beta$-thalassemic patients. These findings are consistent with those of Adil et al. and Mirhosseini et al. $[7,14]$.

The serum corrected calcium level was considerably low in our patients. Our results were in concurrence with Shamshirsaz et al., Aleem et al., Zamboni et al., and Vogiatzi et al., who also found significant hypocalcaemia in their thalassemic patients $[9,15-17]$. The main explanation of hypocalcaemia is endocrinopathy secondary to hemosiderosis. However, chelation therapy in addition to advanced liver diseases may also contribute to hypocalcemia. On the contrary, some authors found no significant difference between the patients and controls in serum calcium level $[18,19]$.

In relation to inorganic phosphorous level, we found that majority had normal levels; only $19.4 \%$ had hypophosphatemia. The possible explanation of hypophosphatemia is secondary to hyperparathyroidism (8.3\%) in our series. These findings were analogous to studies that reported that phosphorous levels were within the normal range in patients compared to controls [20]. On the contrary, some researchers reported significantly higher serum phosphorous levels in thalassemic patients than the control groups $[21,22]$. In the present study, low serum phosphorus positively correlated with high ferritin, but we could not ascertain its significance in our thalassemic patients.

We also determined that low calcium is associated with raised indirect bilirubin levels $(P>0.05)$. In normal individuals, calcium and bilirubin can react to form calcium bilirubinate [23]. Serum calcium complexes with indirect bilirubin and thereby decreases the concentration of serum calcium levels [23].

Thalassemic patients show marked deficiency $(72.2 \%)$ of 25 -hydroxy vitamin D in our study. Napoli et al. found that $9.6 \%$ of thalassemic patients had vitamin D insufficiency in Italian thalassemics [24]. Low serum 25 -hydroxy vitamin D levels have also been reported previously in $\beta$-thalassemic patients by many investigators [25-27]. This deficiency has been attributed to malabsorption of vitamin $\mathrm{D}$ as well as inadequate dietary intake [28-30]. Another plausible explanation is hepatic dysfunctions which lead to defective hydroxylation of vitamin D resulting in decreased level [31]. Other authors also reported that the etiology of 25-OH-D deficiency might be the hepatic iron-overload rather than the dysfunctioning of endocrine tissues [32].

In conclusion, BTM patients have markedly deranged biochemical profile. Aggressive nutritional support and calcium/vitamin D supplementation are highly recommended for these patients. Regular monitoring of biochemical mineral profile is also recommended. Proper monitoring and treatment will definitely improve skeletal status in these patients. 


\section{Conflict of Interests}

The authors declare that they have no conflict of interests regarding the publication of this paper.

\section{Acknowledgment}

The authors are grateful to the patients who have participated in this study.

\section{References}

[1] S. Sultan, S. M. Irfan, R. Zeeshan, J. Kaker, and A. Kidwai, "Zinc status and its correlation with basic parameters in transfusion dependent thalassemic patients: a Pakistani perspective," Iranian Journal of Blood and Cancer, vol. 6, no. 3, pp. 113-118, 2014.

[2] S. Sultan, S. M. Irfan, J. Kakar, and R. Zeeshan, "Effect of iron chelator desferrioxamine on serum zinc levels in patients with beta thalassemia major," The Malaysian Journal of Pathology, vol. 37, no. 1, pp. 35-38, 2015.

[3] O. S. Salama, Y. A. Al-Tonbary, R. A. Shahin, and O. A. Sharaf Eldeen, "Unbalanced bone turnover in children with $\beta$-thalassemia," Hematology, vol. 11, no. 3, pp. 197-202, 2006.

[4] M. Saboor, F. Qudsia, K. Qamar, and M. Moinuddin, "Levels of calcium, corrected calcium, alkaline phosphatase and inorganic phosphorus in patients' serum with $\beta$-thalassemia major on subcutaneous deferoxamine," Journal of Hematology \& Thromboembolic Diseases, vol. 2, article 130, 2014.

[5] I. Aslan, D. Canatan, N. Balta et al., "Bone mineral density in thalassemia major patients from Antalya, Turkey," International Journal of Endocrinology, vol. 2012, Article ID 573298, 4 pages, 2012.

[6] S. Malik, S. Syed, and N. Ahmed, "Complications in transfusion-dependent patients of $\beta$-thalassemia major," Pakistan Journal of Medical Sciences, vol. 25, no. 4, pp. 678-682, 2009.

[7] A. Adil, Z. A. Sobani, A. Jabbar, S. N. Adil, and S. Awan, "Endocrine complications in patients of beta thalassemia major in a tertiary care hospital in Pakistan," Journal of the Pakistan Medical Association, vol. 62, no. 3, pp. 307-310, 2012.

[8] A. A. Hamidieh, B. Moradbeag, F. Pasha, M. Jalili, M. Hadjibabaie, and M. Keshavarznia, "High prevalence of hypoparathyroidism in patients with beta-thalassemia major," International Journal of Hematology-Oncology and Stem Cell Research, vol. 3, no. 3, pp. 17-20, 2009.

[9] A. A. Shamshirsaz, M. R. Bekheirnia, M. Kamgar et al., "Metabolic and endocrinologic complications in beta-thalassemia major: a multicenter study in Tehran," BMC Endocrine Disorders, vol. 3, article 4, 2003.

[10] G. A. Sleem, I. S. Al-Zakwani, and M. Almuslahi, "Hypoparathyroidism in adult patients with $\beta$-thalassemia major," Sultan Qaboos University Medical Journal, vol. 7, no. 3, pp. 215-218, 2007.

[11] J. P. S. Chern and K.-H. Lin, "Hypoparathyroidism in transfusion-dependent patients with $\beta$-thalassemia," Journal of Pediatric Hematology/Oncology, vol. 24, no. 4, pp. 291-293, 2002.

[12] N. G. Angelopoulos, A. Goula, G. Rombopoulos et al., "Hypoparathyroidism in transfusion-dependent patients with $\beta$-thalassemia," Journal of Bone and Mineral Metabolism, vol. 24, no. 2, pp. 138-145, 2006.

[13] M. Peacock, "Calcium metabolism in health and disease," Clinical Journal of the American Society of Nephrology, vol. 5, supplement 1, pp. S23-S30, 2010.
[14] N. Z. Mirhosseini, S. Shahar, M. Ghayour-Mobarhan et al., "Bone-related complications of transfusion-dependent beta thalassemia among children and adolescents," Journal of Bone and Mineral Metabolism, vol. 31, no. 4, pp. 468-476, 2013.

[15] A. Aleem, A.-K. Al-Momen, M. S. Al-Harakati, A. Hassan, and I. Al-Fawaz, "Hypocalcemia due to hypoparathyroidism in $\beta$ thalassemia major patients," Annals of Saudi Medicine, vol. 20, no. 5-6, pp. 364-366, 2000.

[16] G. Zamboni, P. Marradi, F. Tagliaro, R. Dorizzi, and L. Tatò, "Parathyroid hormone, calcitonin and vitamin D metabolites in beta-thalassaemia major," European Journal of Pediatrics, vol. 145, no. 1-2, pp. 133-136, 1986.

[17] M. G. Vogiatzi, K. A. Autio, J. E. Mait, R. Schneider, M. Lesser, and P. J. Giardina, "Low bone mineral density in adolescents with $\beta$-thalassemia," Annals of the New York Academy of Sciences, vol. 1054, pp. 462-466, 2005.

[18] P. Mahachoklertwattana, A. Chuansumrit, L. Choubtum, A. Sriphrapradang, R. Sirisriro, and R. Rajatanavin, "Bone mineral density in children and young adults with $\beta$-thalassemia trait," Journal of Pediatric Endocrinology and Metabolism, vol. 15, no. 9, pp. 1531-1535, 2002.

[19] M. Di Stefano, P. Chiabotto, C. Roggia et al., "Bone mass and metabolism in thalassemic children and adolescents treated with different iron-chelating drugs," Journal of Bone and Mineral Metabolism, vol. 22, no. 1, pp. 53-57, 2004.

[20] E. Eren and N. Yilmaz, "Biochemical markers of bone turnover and bone mineral density in patients with $\beta$-thalassaemia major," International Journal of Clinical Practice, vol. 59, no. 1, pp. 46-51, 2005.

[21] A. H. Al-Elq and H. H. Al-Saeed, "Endocrinopathies in patients with thalassemias," Saudi Medical Journal, vol. 25, no. 10, pp. 1347-1351, 2004.

[22] A. T. Soliman, N. El Banna, M. A. Fattah, M. M. ElZalabani, and B. M. Ansari, "Bone mineral density in prepubertal children with $\beta$-thalassemia: correlation with growth and hormonal data," Metabolism: Clinical and Experimental, vol. 47, no. 5, pp. 541-548, 1998.

[23] O. S. Salama, Y. A. Al-Tonbary, R. A. Shahin, and O. A. Eldeen, "Unbalanced bone turnover in children with $\beta$-thalassemia," Hematology, vol. 11, no. 3, pp. 197-202, 2006.

[24] G. M. Chan, K. O. Ash, W. Hentschel, and J. Wu, "Effects of bilirubin on ionized calcium," Clinical Chemistry, vol. 27, no. 1, pp. 204-205, 1981.

[25] N. Napoli, E. Carmina, S. Bucchieri, C. Sferrazza, G. B. Rini, and G. Di Fede, "Low serum levels of 25-hydroxy vitamin D in adults affected by thalassemia major or intermedia," Bone, vol. 38, no. 6, pp. 888-892, 2006.

[26] A. Soliman, A. Adel, M. Wagdy, M. Al Ali, and N. ElMulla, "Calcium homeostasis in 40 adolescents with beta-thalassemia major: a case-control study of the effects of intramuscular injection of a megadose of cholecalciferol," Pediatric Endocrinology Reviews, vol. 6, no. 1, pp. 149-154, 2008.

[27] S. Tsitoura, N. Amarilio, P. Lapatsanis, S. Pantelakis, and S. Doxiadis, "Serum 25-hydroxyvitamin D levels in thalassaemia," Archives of Disease in Childhood, vol. 53, no. 4, pp. 347-348, 1978.

[28] M. G. Vogiatzi, E. A. Macklin, F. L. Trachtenberg et al., "Differences in the prevalence of growth, endocrine and vitamin $\mathrm{D}$ abnormalities among the various thalassaemia syndromes in North America," British Journal of Haematology, vol. 146, no. 5, pp. 546-556, 2009. 
[29] S. Tsitoura, N. Amarilio, P. Lapatsani, S. Pantelakis, and S. Doxiadis, "Serum 25 hydroxy vitamin D levels in thalassemia," Archives of Disease in Childhood, vol. 53, pp. 347-348, 1978.

[30] S. Malik, S. Syed, and N. Ahmed, "Complications in transfusion-dependent patients of $\beta$-thalassemia major," Pakistan Journal of Medical Sciences, vol. 25, no. 4, pp. 678-682, 2009.

[31] F. M. Fahim, K. Saad, E. A. Askar, E. N. Eldin, and A. F. Thabet, "Growth parameters and vitamin D status in children with thalassemia major in upper Egypt," International Journal of Hematology-Oncology and Stem Cell Research, vol. 7, no. 4, pp. 10-14, 2013.

[32] A. G. Pirinççioğlu, V. Akpolat, O. Köksal, K. Haspolat, and M. Söker, "Bone mineral density in children with beta-thalassemia major in Diyarbakir," Bone, vol. 49, no. 4, pp. 819-823, 2011. 


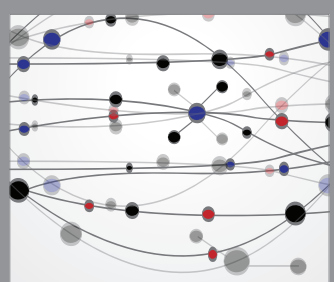

The Scientific World Journal
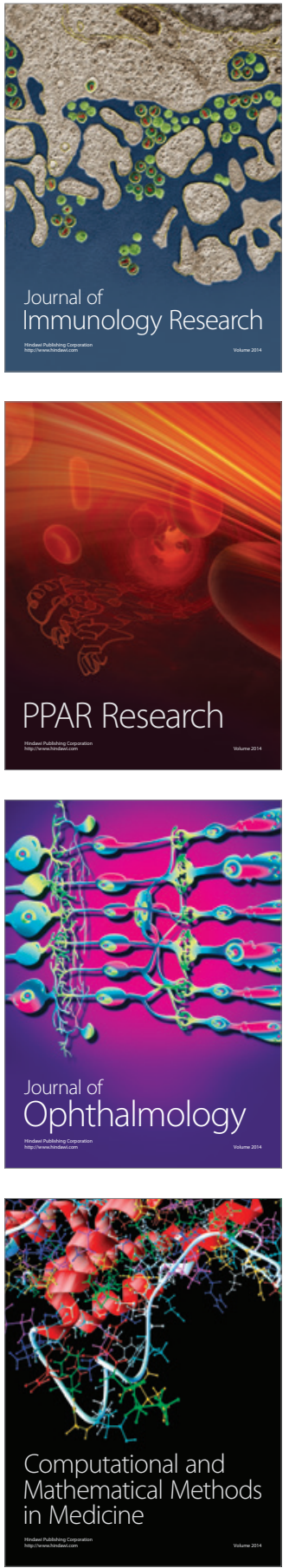

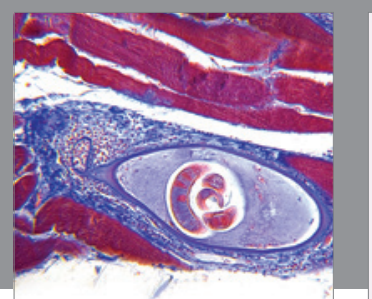

Gastroenterology Research and Practice

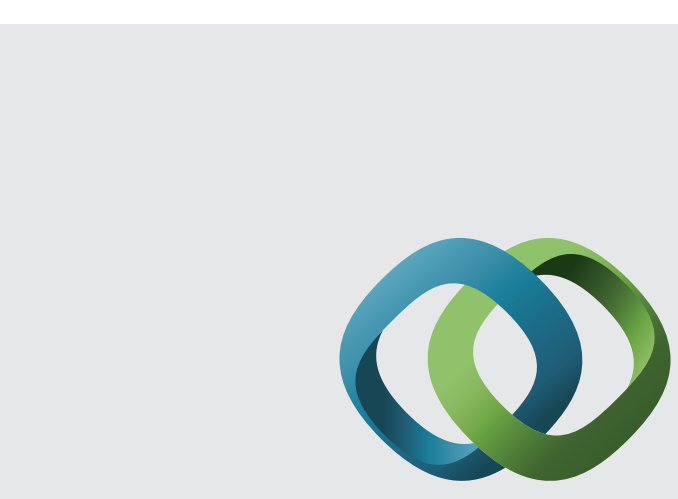

\section{Hindawi}

Submit your manuscripts at

http://www.hindawi.com
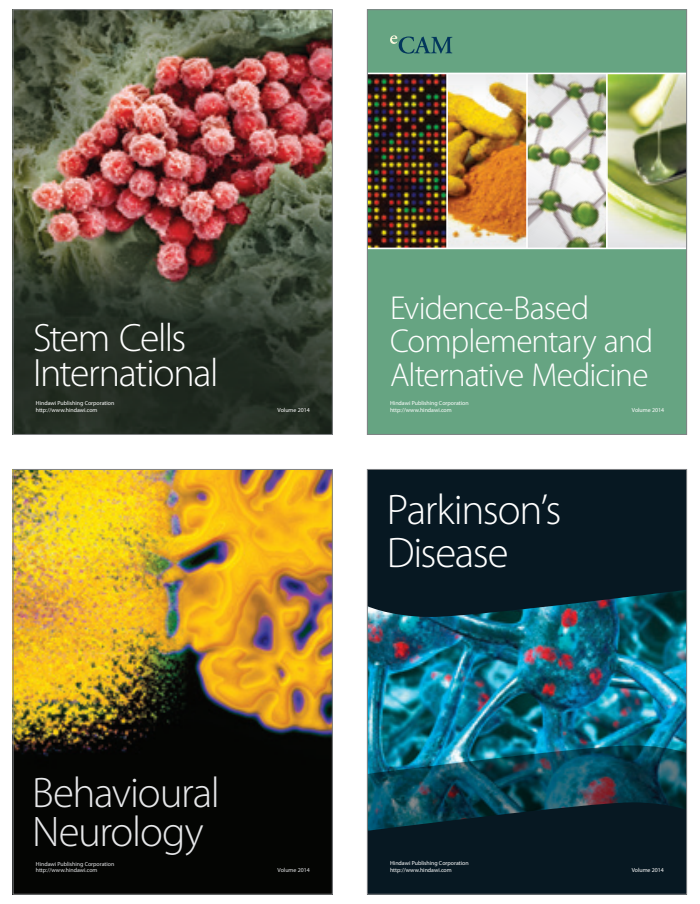
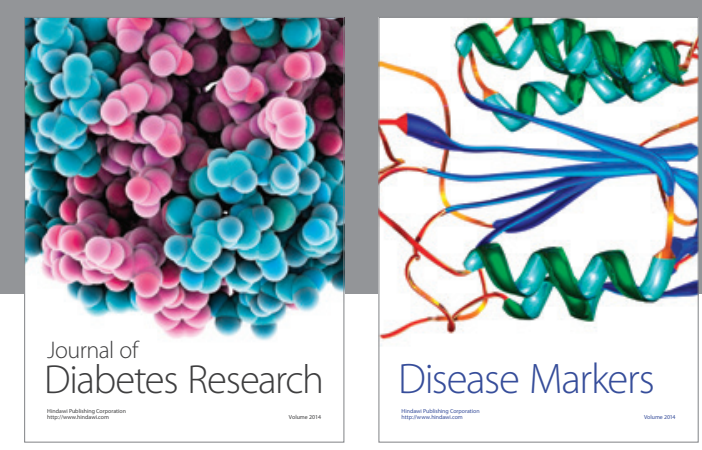

Disease Markers
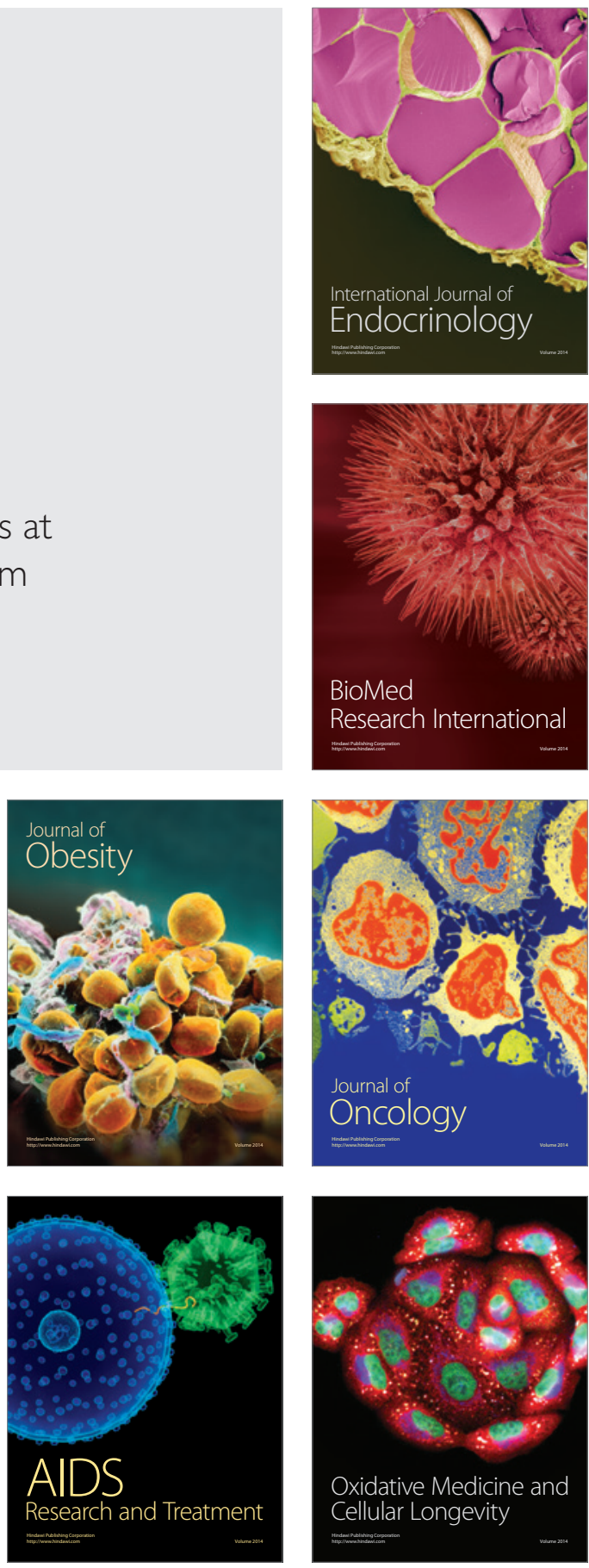